\title{
EXPERIMENTAL AND NUMERICAL ASSESSMENT OF THE DYNAMICAL BEHAVIOUR OF A FOOTBRIDGE UNDER HUMAN-INDUCED LOADS
}

\author{
José Guilherme Santos da Silva ${ }^{1}$, Gilvan Lunz Debona ${ }^{2}$ and Cássio Marques Rodrigues Gaspar ${ }^{2}$ \\ ${ }^{1}$ State University of Rio de Janeiro, UERJ, Structural Engineering Department, Rio de Janeiro, Brazil \\ ${ }^{2}$ Civil Engineering Post-graduate Programme, PGECIV/UERJ, Rio de Janeiro, Brazil
}

\begin{abstract}
This research aims to perform an experimental and numerical assessment of an existing pedestrian footbridge located in the campus of the State University of Rio de Janeiro (UERJ), Rio de Janeiro/RJ, Brazil. The structural system is based on an internal reinforced concrete footbridge spanning $24.5 \mathrm{~m}$, constituted by concrete beams and slabs and being currently used for pedestrian crossing. The modal testing of the structure was performed by dynamic monitoring through accelerometers installed on the structure as well as by a vibrometer device based on Laser Doppler Vibrometry using the SIMO and SISO acquisition techniques, respectively. Then, these experimental results were calibrated with a numerical model by the use of finite element method (FEM) through the ANSYS program. Afterwards, a forced vibration analysis was performed on the structure based on human-induced loads considering two control groups: the first one is intended to excite the investigated footbridge to cause resonance motion with a controlled step frequency and the second one is related to freely random people crossing the footbridge as it occurs normally during its real life. Thus, the structural system dynamic response in terms of peak accelerations values were evaluated and compared to the current human comfort criteria.
\end{abstract}

\section{Introduction}

The human comfort issue of civil structures has been gaining important relevance in the last decade by several researchers [1-5]. Precisely, regarding the footbridges concern, it has been noticed that most of the as built footbridges natural frequencies lie in the same range of the human frequency step and its upper harmonics. This fact may easily lead these structures to a resonant state motion. Besides, the lowering of their stiffness, modal mass and damping as consequence of the current market design trends have been contributing to the increase of the human discomfort of the pedestrians [5].

Although some design methodologies and human comfort criteria in design stage have been developed in the last decade as AISC [6], Sétra [7] and HiVoSS [8], there is a lack of attention concerning the evaluation and validation of the structure dynamic characteristics in situ [5]. Considering that each as built footbridge is unique prototype [4], some inevitable uncertainties which are difficult to estimate in design stage related to both predicated natural frequencies and damping properties. Therefore, the modal identification of the structure should be applied in order to obtain a more reliable human comfort evaluation as well as to update its properties whether and whenever necessary [5].

In this sense, this paper aims to investigate the dynamic behaviour of an existing pedestrian footbridge built in the seventies (70's) and located in the campus of the State
University of Rio de Janeiro (UERJ), Rio de Janeiro/RJ, Brazil. Thus, the structure modal identification was carried out based on a traditional data acquisition system ADS-2002, manufactured by LYNX Electronic Technology, and also using a Laser Doppler Vibrometry methodology. Then, the numerical model was calibrated with the experimental results, based on the finite element method (FEM) using the ANSYS program [9]. Moreover, the human comfort of the investigated footbridge was evaluated according to the current design criteria [6-8].

\section{Investigated pedestrian footbridge}

The investigated structural model is related to an existing pedestrian footbridge located in the campus of the State University of Rio de Janeiro (UERJ), Rio de Janeiro/RJ, Brazil. The structural system is based on a simply supported internal reinforced concrete footbridge spanning $24.4 \mathrm{~m}$, constituted by concrete beams and slabs, and being currently used for people crossing, see Figures 1 to 6 . The concrete presents a $14 \mathrm{MPa}$ specified compression strength and a $1.78 \times 10^{10} \mathrm{~N} / \mathrm{m}^{2}$ Young's Modulus. The total mass of the structure is equal to $66.2 \mathrm{t}$.

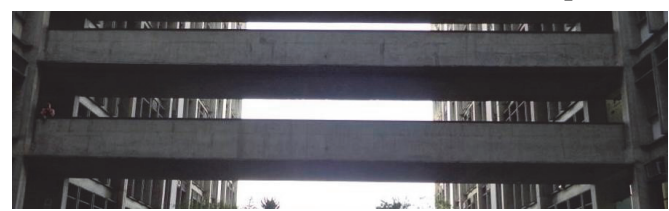

Figure 1. Investigated pedestrian footbridge: lateral view.

\footnotetext{
${ }^{\mathrm{a}}$ José Guilherme Santos da Silva: jgss@uerj.br
} 


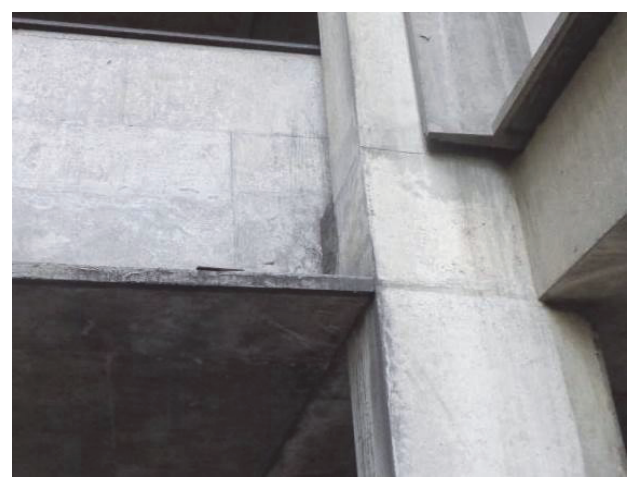

Figure 2. Investigated pedestrian footbridge: support details.

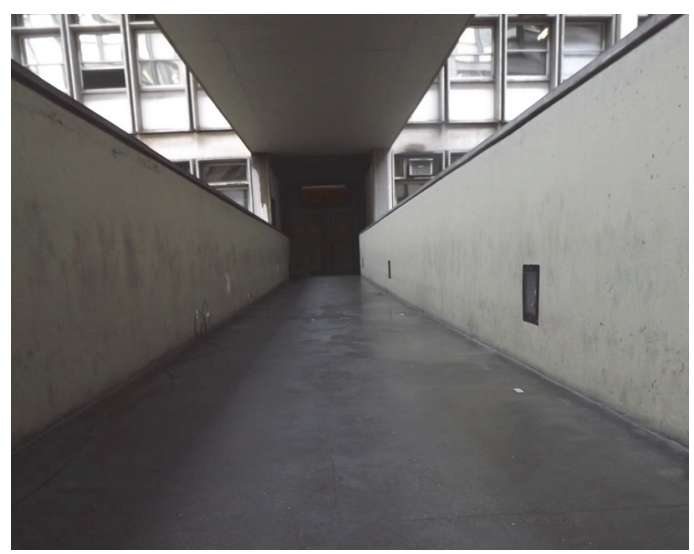

Figure 3. Investigated pedestrian footbridge: front view.

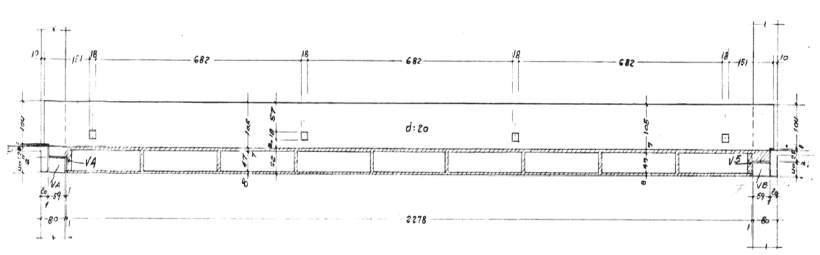

Figure 4. Structural design: front view $(\mathrm{cm})$.

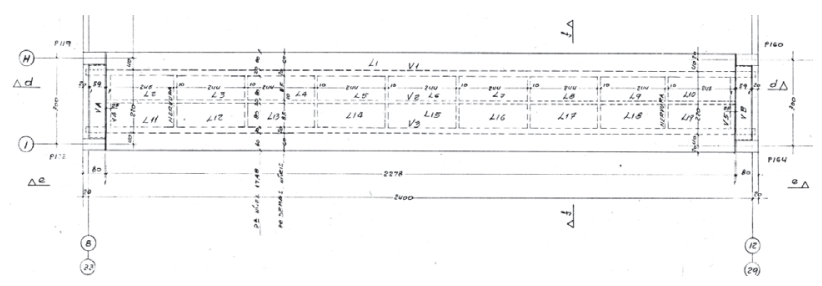

Figure 5. Structural design: top view $(\mathrm{cm})$.

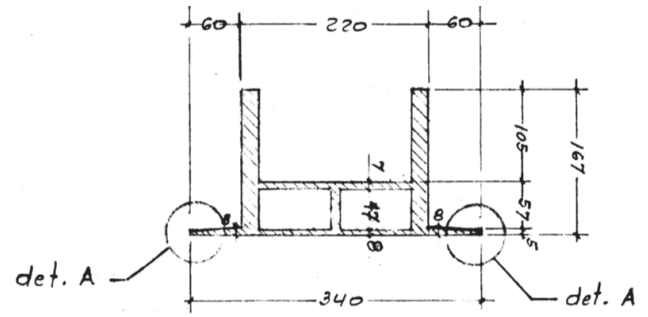

Figure 6. Structural design: cross section (cm).

\section{Numerical modelling of the footbridge}

The developed finite element model adopted the usual mesh refinement techniques present in finite element method simulations, based on the ANSYS program [9], as illustrated in Figures 7 to 9. In this computational model, all the reinforced concrete sections were represented by shell finite elements (SHELL63). This finite element has both bending and membrane capabilities. The element has six degrees of freedom at each node: translations in the nodal $\mathrm{x}, \mathrm{y}$, and $\mathrm{z}$ directions and also rotations about the nodal $\mathrm{x}, \mathrm{y}$, and $\mathrm{z}$ axes.

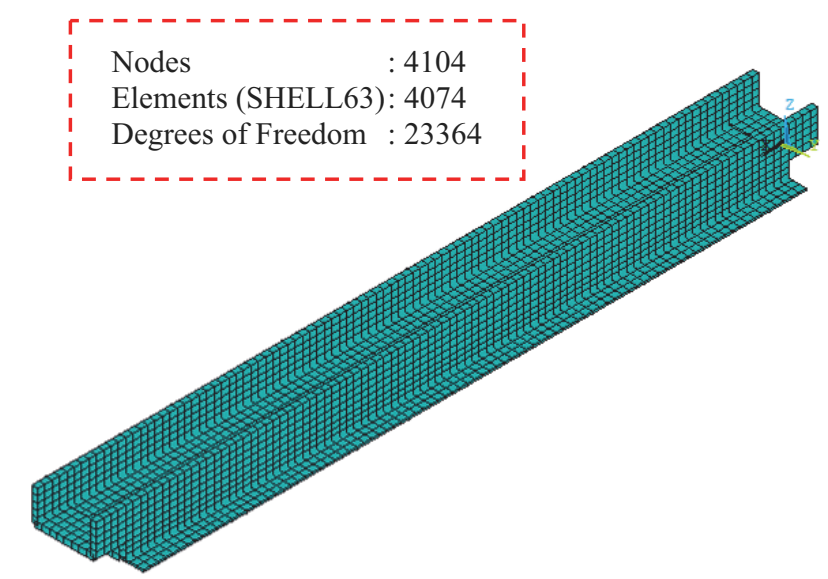

Figure 7. Finite element model three dimensional view.

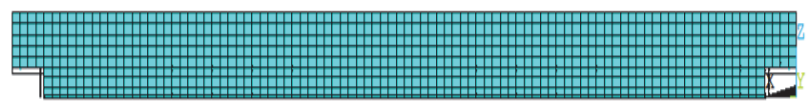

Figure 8. Finite element model lateral view.

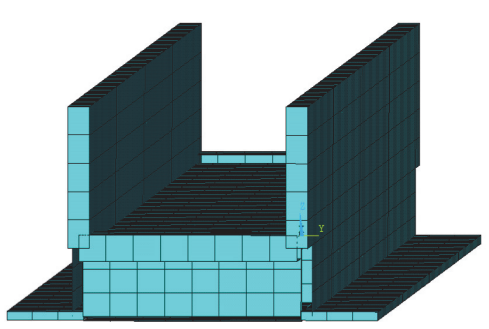

Figure 9. Finite element model front view.

\section{Experimental modal analysis}

The experimental modal analysis of the studied footbridge was conducted by dynamic monitoring through accelerometers installed on the structure as well as by a vibrometer device based on a Laser Doppler Vibrometry methodology. Firstly, the free vibration test was carried out by the simplest manner i.e. one person of $95 \mathrm{~kg}$ jumped at the footbridge centre. The single input multiple output method (SIMO) was employed in this step. Therefore, the free vibration results were obtained using three resistive Kyowa accelerometers located at the middle and both one quarter of the footbridge, see Figure 10. A data acquisition system ADS-2002 manufactured 
by LYNX Electronic Technology was used in this investigation, see Figure 10. This system is based on signal conditioners that turn the sign of the variation in electrical engineering value (specific deformation, acceleration and force), controlled by a computer.

Secondly, a single-input single-output (SISO) test was performed combining the Polytec vibrometer PDV-100 and a Dytran impact hammer, as shown in Figure 11. The basic functioning of the Laser Doppler Vibrometry methodology is related to a laser beam focused on the tested structure so that the relative movement between the laser and the structure causes the presence of the Doppler effect i.e. the relative change in wavelength and frequency of a wave when the observer and the source are moving [10].

Before the experimental modal test performance, the modal product of the numerical modes was made, in order to find out the possible footbridge optimum common point where the impact hammer could excite most of the structure vibration modes. After that, six points were chosen in this analysis, as illustrated in Figure 12, aiming to obtain the Frequency Response Functions (FRFs) of the investigated footbridge.

The FRFs corresponding the output responses associated to the three accelerometers used in the experimental modal analysis of the footbridge are presented in Figures 13 to 15 (ADS-2002 system) and Figures 16 to 18 (PDV-100 system). The damping ratio of the three first bending modes was gathered by the logarithmic decrement method. The modal damping ratios are equal to $1.80 \%\left(1^{\text {st }}\right.$ mode shape $), 1.15 \%\left(2^{\text {nd }}\right.$ mode shape $)$ and $1.02 \%$ ( $3^{\text {rd }}$ mode shape $)$.
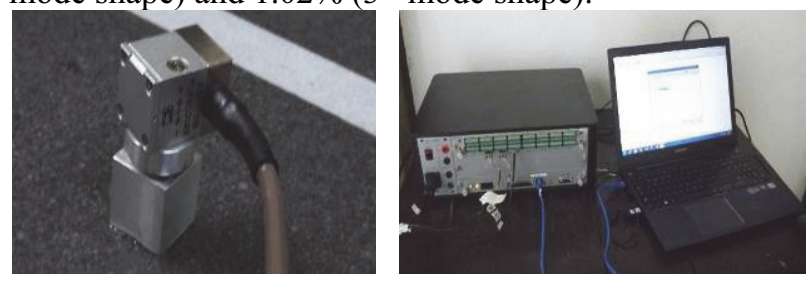

Figure 10. Accelerometers, ADS-2002 system and computer.
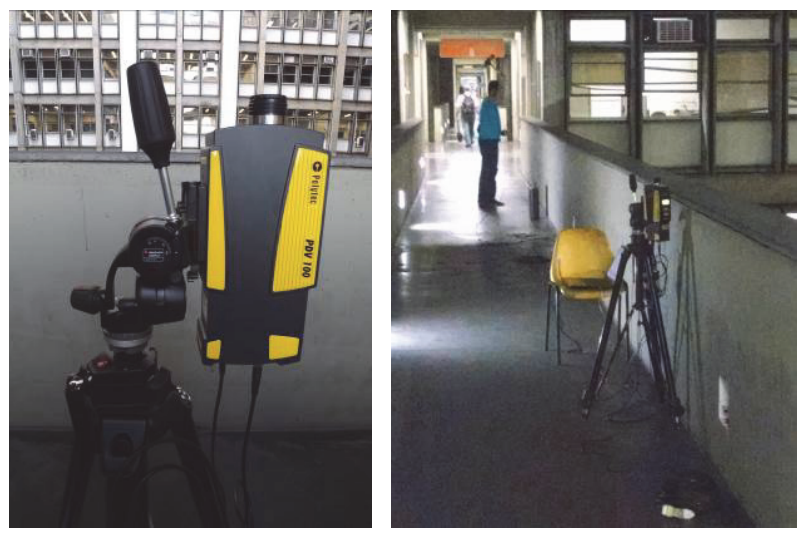

Figure 11. PDV-100 system.

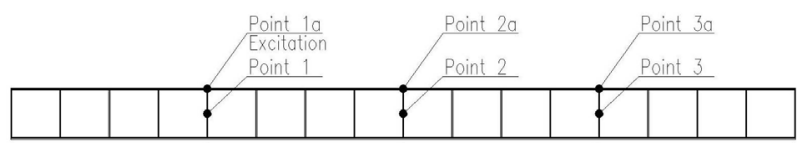

$1 / 4 \operatorname{SPAN} \longrightarrow, 1 / 4 \operatorname{SPAN} \longrightarrow, 1 / 4 \operatorname{SPAN} \longrightarrow, 1 / 4 \operatorname{SPAN} \square$

Figure 12. Point measurements on the investigated footbridge.

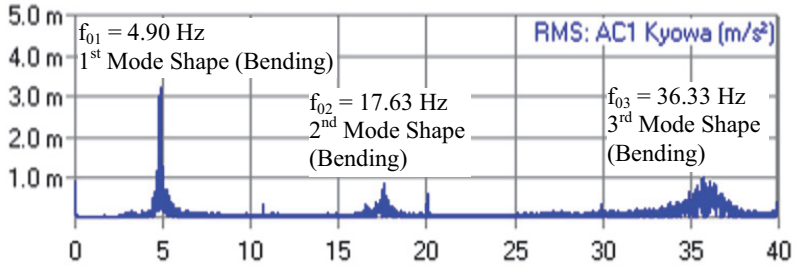

Figure 13. ADS-2002 system: FRF at Point 1 (1/4 Span).

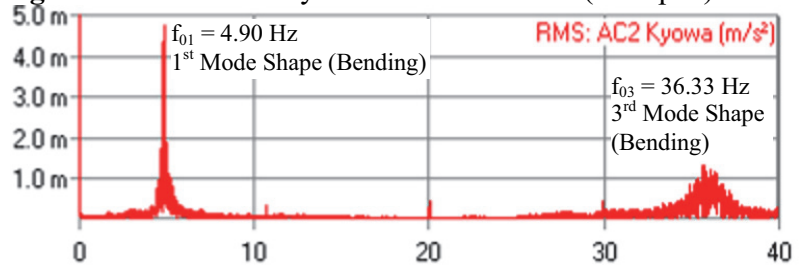

Figure 14. ADS-2002 system: FRF at Point 2 (1/2 Span).

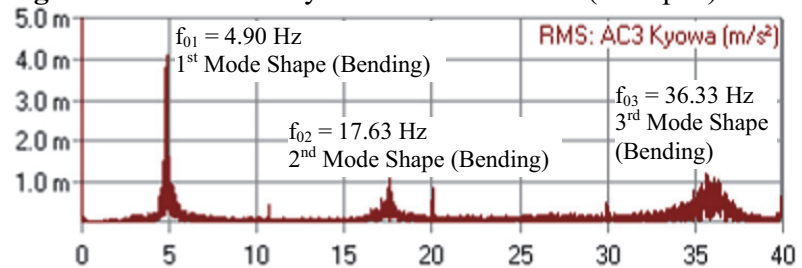

Figure 15. ADS-2002 system: FRF at Point 3 (3/4 Span).

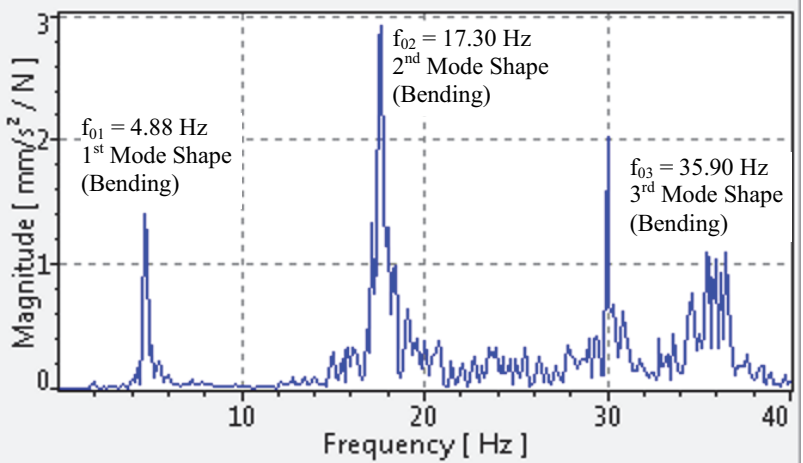

Figure 16. PDV-100 system: FRF at Point 1 (1/4 Span).

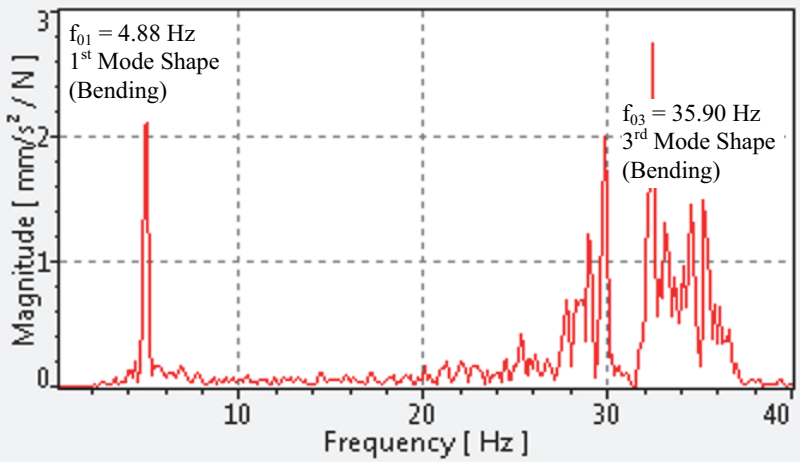

Figure 17. PDV-100 system: FRF at Point 2 (1/2 Span).

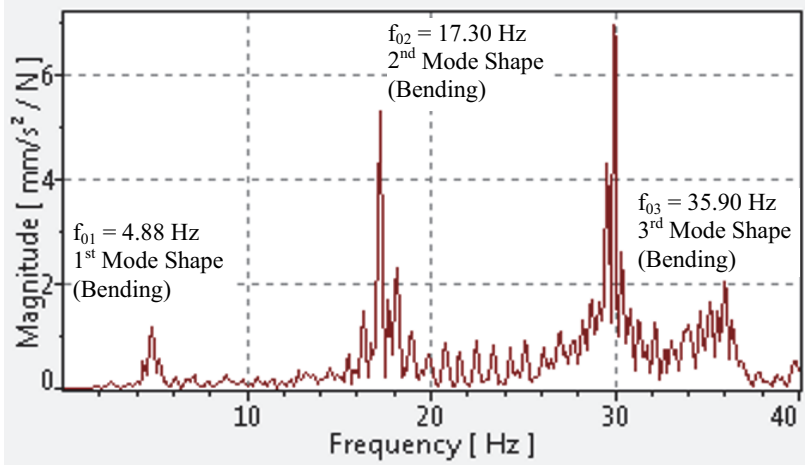

Figure 18. PDV-100 system: FRF at Point 3 (3/4 Span). 


\section{Footbridge system vibration analysis}

The footbridge natural frequencies, vibration modes and peak accelerations values were determined with the aid of the numerical simulations, based on the finite element method using the ANSYS program [9] and also compared with the experimental results, according to Table 1 and Figures 19 to 21 .

Based on the Table 1 results it can be seen that the obtained experimental results presented a good agreement to each other as well as to the numerical ones. Moreover, it must be highlighted that footbridge fundamental natural frequency lies in the human walking frequency range. Thus, a possible resonance situation may be expected.

Table 1. Investigated footbridge natural frequencies.

\begin{tabular}{|c|c|c|c|c|c|}
\hline \multirow{2}{*}{$\begin{array}{c}\text { Natural } \\
\text { Frequency }\end{array}$} & \multirow{2}{*}{$\begin{array}{c}\text { Finite } \\
\text { Element } \\
\text { Model } \\
\end{array}$} & \multicolumn{2}{|c|}{$\begin{array}{c}\text { Experimental } \\
(\mathbf{H z})\end{array}$} & \multicolumn{2}{|c|}{$\begin{array}{c}\text { Differences } \\
(\mathbf{\%})\end{array}$} \\
\cline { 3 - 6 } & $\mathbf{2 0 0 2}$ & $\begin{array}{c}\text { PDV } \\
\mathbf{1 0 0}\end{array}$ & $\begin{array}{c}\text { ADS } \\
\mathbf{2 0 0 2}\end{array}$ & $\begin{array}{c}\text { PDV } \\
\mathbf{1 0 0}\end{array}$ \\
\hline $\mathrm{f}_{01}$ & 4.898 & 4.900 & 4.880 & 0.04 & 0.37 \\
\hline $\mathrm{f}_{02}$ & 15.923 & 17.630 & 17.300 & 10.72 & 8.65 \\
\hline $\mathrm{f}_{03}$ & 32.154 & 36.330 & 35.900 & 12.99 & 11.65 \\
\hline
\end{tabular}

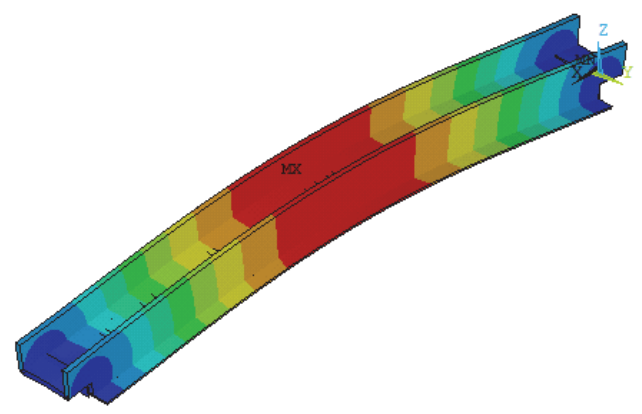

Figure 19. $1^{\text {st }}$ Numerical vibration mode (Bending).

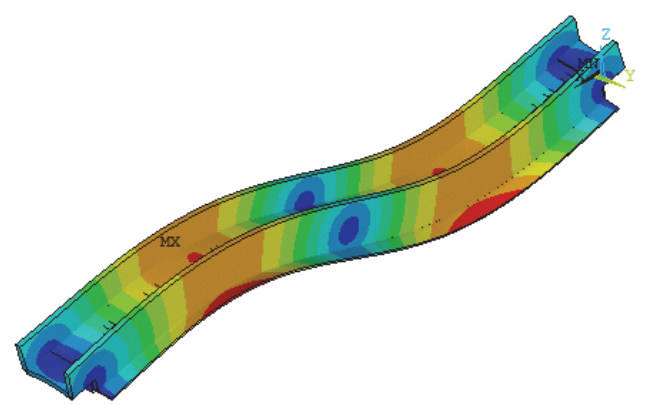

Figure 20. $2^{\text {st }}$ Numerical vibration mode (Bending).

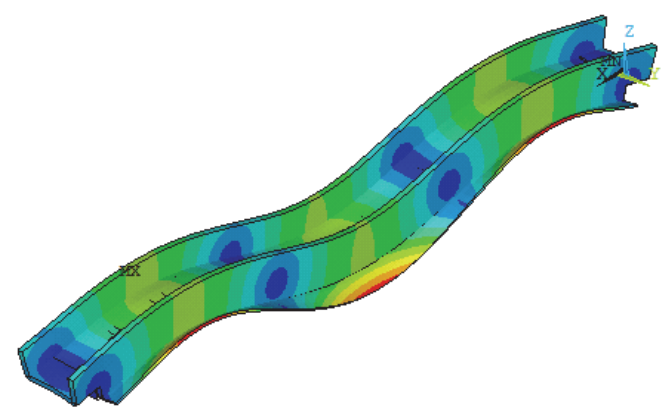

Figure 21. $3^{\text {st }}$ Numerical vibration mode (Bending).

\section{Experimental forced vibration analysis}

The human walking excitation on the investigated reinforced concrete pedestrian footbridge was performed based on two control groups: the first one is intended to excite the structural model to cause a resonance motion with a controlled step frequency; the second one is related to freely random people crossing the footbridge as it occurs normally during its real life. The obtained data related to these experimental tests were recorded by the acquisition system ADS-2002 using the three resistive Kyowa accelerometers at Point 2, see Figure 12. The experimental results are illustrated in Figures 22 to 33.

Initially, a metronome value was set in $147 \mathrm{bpm}$ ( $\mathrm{f}=$ $2.45 \mathrm{~Hz}$ ) so that the second harmonic of the human step $(2 \times 2.45 \mathrm{~Hz}=4.90 \mathrm{~Hz})$ of eight persons crossing synchronously the pedestrian footbridge could force a resonant state motion on the structural model with the first vertical vibration mode $\left(\mathrm{f}_{01}=4.90 \mathrm{~Hz}\right.$, see Table 1$)$. After that, in order to perform two additional tests, the metronome value was changed to $120 \mathrm{bpm}$ to induce the pedestrians to cross the structure in normal walking ( $\mathrm{f}=2$ $\mathrm{Hz}$ ) and also the metronome was set to $102 \mathrm{bpm}$ to pedestrians crossing the footbridge in slow walking ( $\mathrm{f}=$ $1.7 \mathrm{~Hz}$ ). Afterwards, the last experiment was carried out so that nine pedestrians walked freely on the structure.

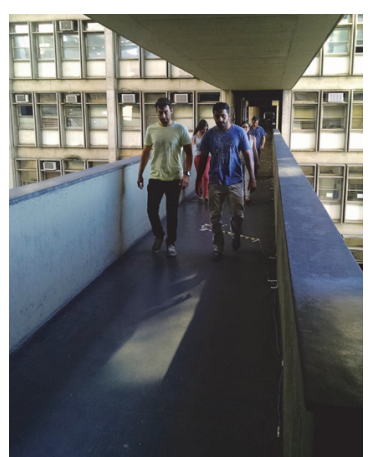

Figure 22. Human walking tests ( $\mathrm{f}=1.7 \mathrm{~Hz}$ : slow walking).

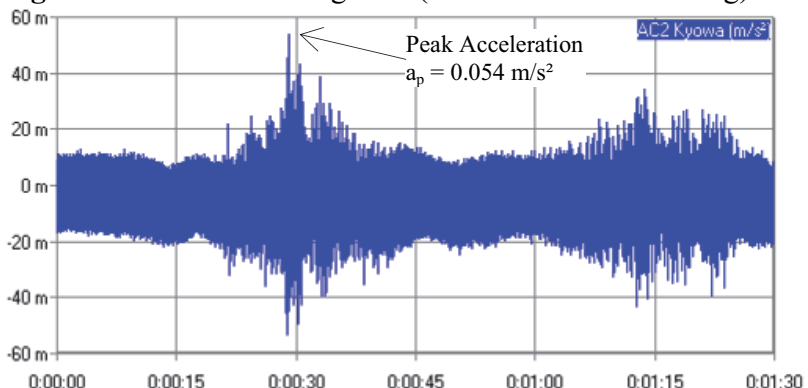

Figure 23. Footbridge vertical acceleration in time domain ( $\mathrm{f}=$ 1.7 Hz: slow walking): Point 2 (1/2 Span).

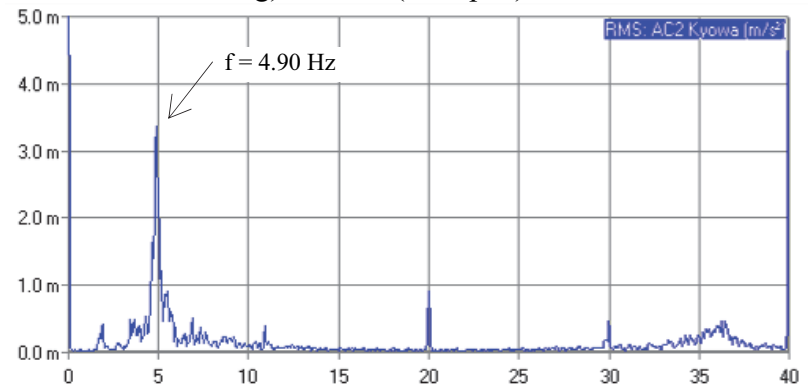

Figure 24. Footbridge vertical acceleration in frequency domain ( $\mathrm{f}=1.7 \mathrm{~Hz}$ : slow walking): Point 2 (1/2 Span). 


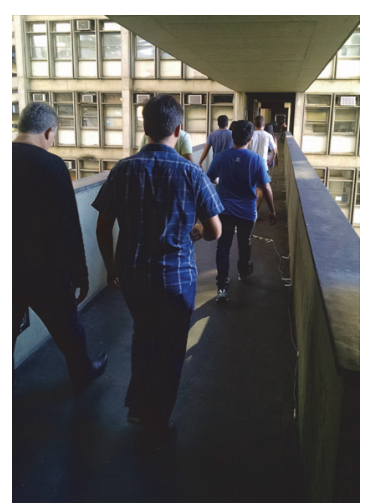

Figure 25. Human walking tests ( $\mathrm{f}=2 \mathrm{~Hz}$ : normal walking).

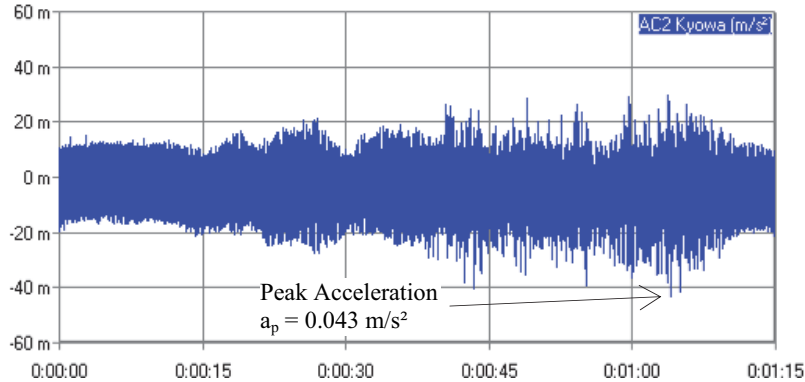

Figure 26. Footbridge vertical acceleration in time domain ( $\mathrm{f}=$ $2 \mathrm{~Hz}$ : normal walking): Point 2 (1/2 Span).

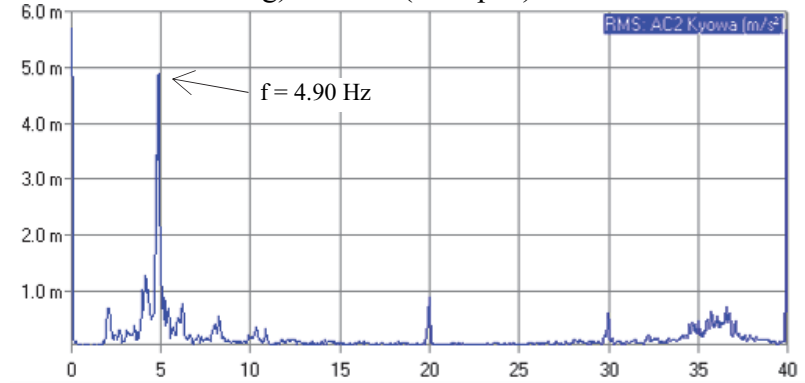

Figure 27. Footbridge vertical acceleration in frequency domain ( $\mathrm{f}=2 \mathrm{~Hz}$ : normal walking): Point 2 (1/2 Span).

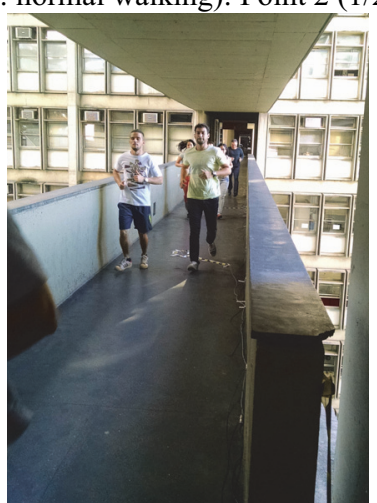

Figure 28. Human walking tests $(f=2.45 \mathrm{~Hz}$ : resonance $)$.

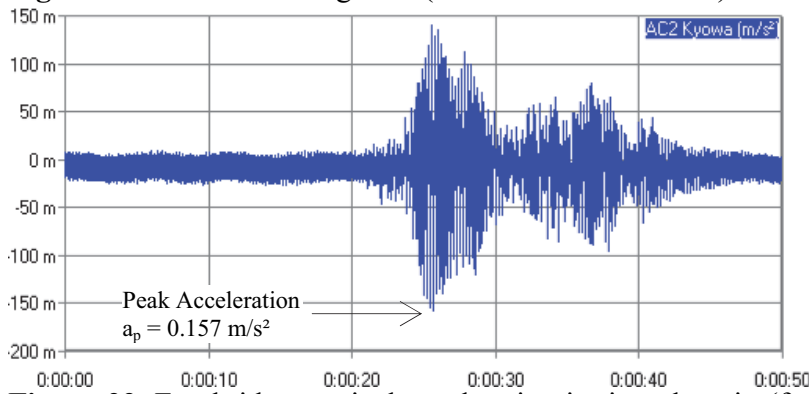

Figure 29. Footbridge vertical acceleration in time domain ( $\mathrm{f}=$ $2.45 \mathrm{~Hz}$ : resonance situation): Point 2 (1/2 Span.

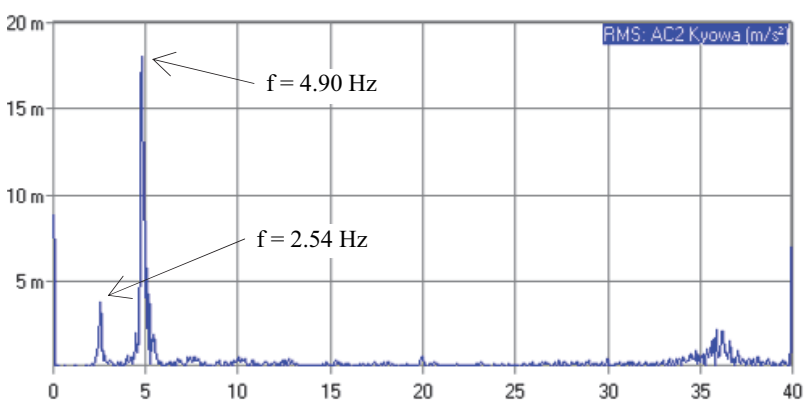

Figure 30. Footbridge vertical acceleration in frequency domain ( $f=2.45 \mathrm{~Hz}$ : resonance situation): Point 2 (1/2 Span.

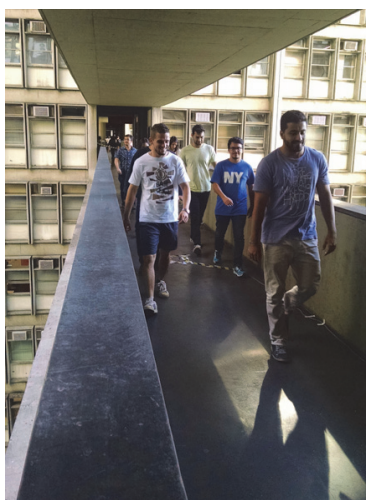

Figure 31. Experimental test related to human random walking.

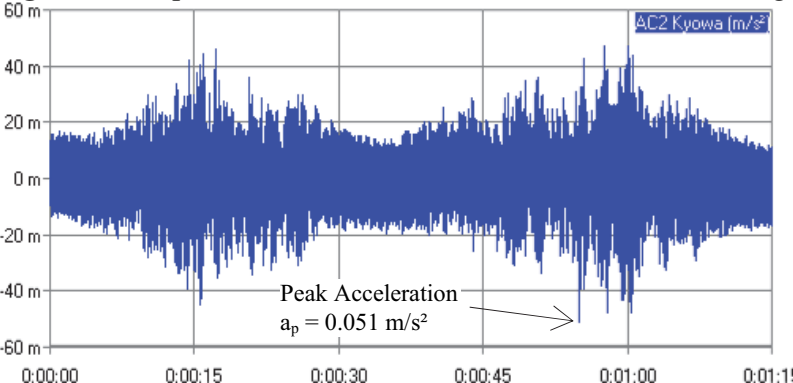

Figure 32. Footbridge vertical acceleration in time domain based on pedestrians random walking: Point 2 (1/2 Span).

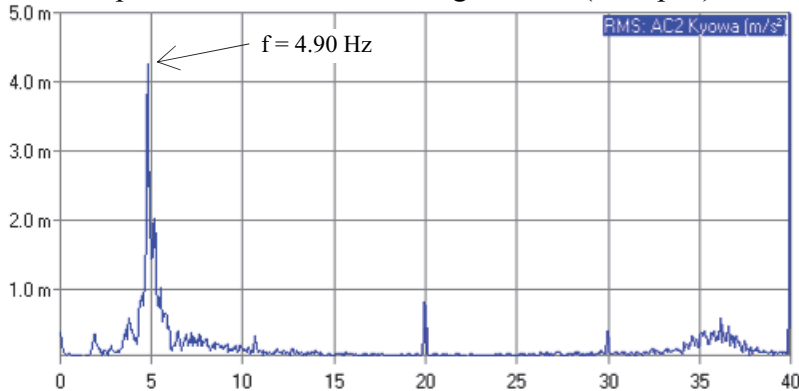

Figure 33. Footbridge vertical acceleration in frequency domain based on pedestrians random walking: Point $2(1 / 2$ Span).

The obtained results from all these experimental tests are shown in Figures 22 to 33 in time and frequency domain, respectively. These results correspond to the accelerometer at the middle of the investigated footbridge (Point 2: 1/2 Span, see Figure 12).

It must be emphasised that the " $\mathrm{m}$ " in the $\mathrm{Y}$ axes (Amplitude in $\mathrm{m} / \mathrm{s}^{2}$ ) of the Figures 22 to 33, in time domain, correspond to the prefix "milli" $\left(10^{-3}\right)$. On the other hand, the $\mathrm{X}$ axes present the time in seconds and frequency in $\mathrm{Hz}$, respectively, according to each analysis. 
The maximum acceleration values found in this experimental investigation are respectively equal to 0.054 $\mathrm{m} / \mathrm{s}^{2}$ for 8 people in slow walking $\left(\mathrm{a}_{\mathrm{p}}=0.054 \mathrm{~m} / \mathrm{s}^{2} / \mathrm{f}=1.7\right.$ $\mathrm{Hz}), 0.043 \mathrm{~m} / \mathrm{s}^{2}$ for 8 people in normal walking $\left(\mathrm{a}_{\mathrm{p}}=\right.$ $\left.0.043 \mathrm{~m} / \mathrm{s}^{2} / \mathrm{f}=2 \mathrm{~Hz}\right), 0.157 \mathrm{~m} / \mathrm{s}^{2}$ for 8 people in resonance walking $\left(a_{p}=0.157 \mathrm{~m} / \mathrm{s}^{2} / \mathrm{f}=2.45 \mathrm{~Hz}\right)$ and also $0.051 \mathrm{~m} / \mathrm{s}^{2}$ for 9 people walking freely on the footbridge concrete slab (random walking).

\section{Human comfort evaluation}

The results of all human walking tests are summarised in Table 2. It can be noted from Table 2 results that the human comfort criterion proposed by the Sétra technical guide [7] was satisfied for the four investigated walking situations. It means that the experimental acceleration values lie in range of 0.0 to $0.5 \mathrm{~m} / \mathrm{s}^{2}$ which corresponds to a maximum human comfort.

On the other hand, regarding the AISC guide [6], even though the acceleration limit of $0.15 \mathrm{~m} / \mathrm{s}^{2}$ for indoor footbridges is respected by the slow, normal and random walking cases, the peak acceleration value of $0.157 \mathrm{~m} / \mathrm{s}^{2}$ for the resonance case slight overpass this limit $\left(\mathrm{a}_{\lim }=0.15\right.$ $\mathrm{m} / \mathrm{s}^{2}$ ). Nevertheless, it is interesting to point out that a person standing can notice an acceleration value equal to $0.034 \mathrm{~m} / \mathrm{s}^{2}$ and $0.100 \mathrm{~m} / \mathrm{s}^{2}$ as just perceptible and clearly perceptible, respectively [11].

Table 2. Acceleration results of the pedestrian walking tests.

\begin{tabular}{|c|c|l|c|}
\hline \multirow{2}{*}{$\begin{array}{c}\text { Type of } \\
\text { Walking }\end{array}$} & $\begin{array}{c}\text { Peak } \\
\text { acceleration } \\
\mathbf{a}_{\mathbf{p}}\left(\mathbf{m} / \mathbf{s}^{2}\right)\end{array}$ & Sétra $^{*}[7]$ & AISC $^{* *[6]}$ \\
\cline { 3 - 4 } & 0.054 & Maximum & Acceptable \\
\hline Slow & 0.043 & Maximum & Acceptable \\
\hline Normal & 0.157 & Maximum & Unacceptable \\
\hline Resonance & 0.051 & \multicolumn{3}{|c|}{ Maximum } & Acceptable \\
\hline Random & \multicolumn{3}{|c|}{ Human Comfort Criteria } \\
\hline $\begin{array}{l}* \text { acceleration range of } 0-0.5 \mathrm{~m} / \mathrm{s}^{2}: \text { maximum comfort }[7] \\
* * \mathrm{a}_{\lim }=1.5 \% \mathrm{~g}=0.15 \mathrm{~m} / \mathrm{s}^{2}: \text { indoor footbridges [6] } \\
* * \mathrm{a}_{\lim }=5.0 \% \mathrm{~g}=0.49 \mathrm{~m} / \mathrm{s}^{2}: \text { outdoor footbridges [6] }\end{array}$ \\
\hline
\end{tabular}

\section{Conclusions}

This work analysed experimentally and numerically the dynamic behaviour of an internal reinforced concrete pedestrian footbridge spanning $24.4 \mathrm{~m}$, constituted by concrete beams and slabs and being currently used for pedestrian crossing located in the campus of the State University of Rio de Janeiro (UERJ), Rio de Janeiro/RJ, Brazil.

The modal analysis of the investigated structure was performed both experimentally and numerically. The modal testing of the footbridge was performed by dynamic monitoring through accelerometers installed on the concrete slab as well as by a vibrometer device based on a Laser Doppler Vibrometry methodology, using the SIMO and SISO acquisition techniques, respectively. Then, these experimental results were calibrated with a three-dimensional finite element model based on the use of ANSYS program.
It must be emphasized that a good agreement between the experimental and numerical results was obtained. Therefore, the modal analysis indicated that the first natural frequency of the analysed reinforced concrete pedestrian footbridge $\left(\mathrm{f}_{01}=4.88 \mathrm{~Hz}\right)$ lies in the same frequency of the human walking. Consequently, a possible resonant motion case might be expected.

The experimental dynamic analysis, carried out by four human walking loading cases (slow, normal, resonance and random) have shown that the obtained accelerations values satisfied the current human comfort criteria apart from the resonance case $\left(a_{p}=0.157 \mathrm{~m} / \mathrm{s}^{2}\right)$, which slight overpass the AISC proposed limit equal to $0.15 \mathrm{~m} / \mathrm{s}^{2}$ when eight persons crossed the footbridge.

\section{Acknowledgements}

The authors gratefully acknowledge the financial support for this work provided by the Brazilian Science Foundation's CAPES, CNPq and FAPERJ.

\section{References}

1. G. L. Debona, "Biodynamic Walking Model for Vibration Serviceability of Steel-Concrete Composite Footbridges Subjected to PedestrianInduced Loads". PhD Thesis (In Portuguese). Civil Engineering Post-graduate Programme, PGECIV. State University of Rio de Janeiro, UERJ. Rio de Janeiro/RJ, Brazil (2015 - In development)

2. S. Živanović, A. Pavic, P. Reynolds. Vibration serviceability of footbridges under human-induced excitation: a literature review. J Sound Vib 279 (12):1-74 (2005)

3. A. Cunha, E. Caetano. Experimental Modal Analysis of Civil Engineering Structures. Sound and Vibration, V. 40 (6): 12-20 (2006)

4. S. Živanović, A. Pavic, P. Reynolds. Modal testing and finite element model tuning of a lively footbridge structure, Engineering Structures 28 (6): 857-868 (2006)

5. K. V. Nimmena, G. Lombaerta, G. D. Roecka, P. V. D. Broecka. Vibration serviceability of footbridges: Evaluation of the current codes of practice, Engineering Structures 59: 448-461 (2014)

6. T.M. Murray, D.E. Allen, E.E. Ungar. Floor Vibrations due to Human Activity. Steel Design Guide Series. American Institute of Steel Construction, AISC (2003)

7. Technical Guide Footbridges: Assessment of Vibrational Behaviour of Footbridges under Pedestrian Loading. SÉTRA: Service d'Études Techniques des Routes et Autoroutes (2006)

8. Research Fund for Coal and Steel. HiVoSS: Design of footbridges (2008)

9. ANSYS 12.0: ANSYS-Inc. Theory Reference (2010)

10. R. Prislan. Laser doppler vibrometry and modal testing. University of Ljubljana (2008)

11. H. Bachmann et al., Vibration problems in structures - practical guidelines, Basel (Switzerland):Institut für Baustatik und Konstruktion, Birkhäuser (1995) 